\title{
Plut, šut e durak: algumas notas feitas à leitura de M. Bakhtin
}

\author{
Ekaterina Velmezova
}

\begin{abstract}
RESUMO: The aim of this study ${ }^{1}$ is to analyse the social roles of three characters - the swindle, the naive and the buffoon, in Mikhail Bakhtins' research entitled Formy vremeni i xronotopa v romane. Očerki pó istoričeskoj poètike [ Forms of time and chronotopos in novel]. We intend to investigate how these characters can represent different maks and at the same time different ways of answering to rules and to social psychology of russian-soviet people.
\end{abstract}

PALAVRAS-CHAVE: romance, máscaras, chronotopos, fronteiras

Nos primeiros trinta anos do século XX, o problema das fronteiras era um dos mais cruciais para os especialistas em Ciências Humanas. Assim, no âmbito da linguística, a natureza muito convencional das fronteiras que separam as línguas vem se tornando cada vez mais manifesta desde o fim do século XX (mesmo que as primeiras observações sobre esse assunto remontem a uma época mais antiga). Dessa época, datam o conceito de substrato nas línguas e a teoria da hibridação e da mistura de línguas ${ }^{2}$. A análise literária foi igualmente tangenciada por esse problema, com a questão sobre as fronteiras existentes entre os gêneros literários - assim, por exemplo, o pesquisador russo A.N. Veselovskij em suas teorias postulava a ausência de diferenças e, portanto, de fronteiras entre os gêneros poéticos nas sociedades ditas primitivas (VESELOVSKIJ, 2004, p. 200-380). Mesmo que as idéias iniciais sobre o caráter sincrético da arte primitiva já se encontrem nos filósofos da Antiguidade, Veselovskij foi um dos primeiros a reuni-las em uma concepção acabada.

Mikhail. M. Bakhtin também levantou, em suas pesquisas, a questão sobre as fronteiras. Em particular em seus trabalhos de juventude, buscava resolver o problema das fronteiras entre as partes de um todo (celoe) nas categorias de relações mecânicas, "exteriores" versus "interiores"; assim, ele refletia sobre as relações entre a arte, o homem e sua responsabilidade ${ }^{3}$. Por outro lado, Bakhtin levantava igualmente o problema das fronteiras em relação a obras literárias particulares.

Um dos aspectos desse problema era a questão dos laços e das relações complexas entre o autor e os personagens em uma obra literária, assim como aquela das "fronteiras" que os "separam" e dos laços que os "unem". Essa questão aparece e se repete de uma maneira ou de outra em numerosos trabalhos de Bakhtin escritos nos anos de 1920-1930. Neste artigo, analisaremos, a esse respeito, sua pesquisa Formy vremeni i xronotopa $v$ romane. Očerki pó istoričeskoj poètike (Formas do tempo e do chronotopos no romance. Ensaios de poética histórica) escrita em 1937-1938 (Baxtin,1986, p. 121-290). Tratar-se-á, mais precisamente, do sexto capítulo do livro intitulado Funkcii pluta, šuta, duraka v romane (Funções do trapaceiro, do bufão e do bobo no romance).

Ekaterina Velmezova é docente do Departamento de Lingüística Eslava da Universidade de Lausanne e docente da Academia de Ciências de Moscou.

${ }^{1}$ Este texto, cujo título original é Plut, šut et durak: quelques notes prises à la lecture de M. Bakhtine, foi publicado, pela primeira vez, em Fripon, bouffon, sot: pour une relecture de M. Bakhtine no Centre de Traduction Littéraire da Universidade de Lausanne, 2008.

${ }^{2}$ Conforme a noção de Sprachmichung em H. Schuchardt (H. Schuchardt, H. Schuchardt-Brevier. Ein Vademekum der allgemeinen Sprachwissenschaft/als Festgabe zum $8^{\circ}$. Geburtstag des Meisters zusammengestellt und eingeleitet von Leo Spitzer, Verlag Max Niemeyer, Halle [Saale], 1922, pp. 128-141), a tese do "caráter misto de todas as línguas" de I.A. Boudouin de Courtenay (I.A. Boduèn de Kurtenè, "Jazykoznanie, ili lingvistika, XIX veka" [1901], in I.A. Boduèn de Kurtenè, Izbrannye trudy, Izdatel'stvo Akademii nauk, Moscou, 1963, vol. I-II. Vol. I, pp. 3-18),o artigo "Sur la notion de mélange des langues" de L.V. Ščerba (L.V. Ščerba, "Sur la notion de mélange des langues", in Jafetičeskij sbornik, 1925, vol. IV, pp. 1-19), a tese sobre o caráter híbrido de todas as línguas em N.Ja. Marr (conforme, em particular, N.Ja. Marr, "Jazykovaja politika jafetičeskoj teorii i udmurtksij jazyk. [k udmurtskoj èkspedicii Naučnoi ssledovatel'skogo instituta narodov Sovetskogo Vostokaj]” [1931], in N.Ja. Marr, Izbrannye raboty. 1933-1937, vol. I-V, Izdatel'stvo gosudarstvennoj akademii istorii material'noj kul'tury [vol. I] - Gosudarstvennoe social'noèkonomičeskoe izdatel'stvo [vol. II-V], Moscou -Leningrado, vol. V, pp. 467-533; p. 516), etc.

${ }^{3}$ A esse respeito, conforme E. Velmezova, "Mikail Bakhtin, o mecânico e as fronteiras", In A. Zandwais (ed.), Mikhail Bakhtin: contribuições para a Filosofia da Linguagem e Estudos Discursivos. Porto Alegre, 2005, p. 73-82 e E. Velmezova, "Mixail Baxtin, Nikolaj Marr i paradigma 'celostnoj nauki'”, in M. Lähteenmäki, H. Dufva, S. Leppänen, P. Varis (Eds.), Proceedings of the XII International Bakhtin Conference. Juväskylä, Finland, 18-22 july 2005, Department of Languages, University of Juväskylä, Finland, 2006, p. 62-77. 
O plut, o šut e o durak ${ }^{4}$, escreve Bakhtin, são os três personagens que tinham um status particular nos gêneros da literatura medieval e que estavam diretamente relacionados às massas populares. Eles desempenharam, em vista disto, um papel importante na evolução do romance na literatura europeia.

Isso se explica pelo fato de que, segundo Bakhtin, a posição do autor no romance (à diferença dos outros gêneros) era, desde o início, muito complexa e problemática. $\mathrm{O}$ autor de romance necessitava de um tipo de "máscara dupla": um dos lados se voltaria para a vida real refletida no romance (era preciso compreender de onde e como o autor contempla e desvenda a vida) (Baxtin, op. cit., p. 196) e o outro seria direcionado aos leitores (a que título, em qual papel e sob que aspecto o autor descreve a vida ao seu redor). Aqui, escreve Bakhtin, transformadas de uma maneira ou de outra, as máscaras do trapaceiro, do bufão e do bobo ajudam o romancista em seu trabalho. O fato é que essas três figuras teriam tradicionalmente o status da "não-participação na vida". Antes de se envolver na vida como o fazem os outros, eles a observam e, de alguma maneira, a "desnudam" (Ibid., p. 197). Por isso, os pontos de vista expressos por eles no romance (e que seriam, na realidade, aqueles do autor oculto e "invisível" escondido por trás de suas máscaras) podem pretender a objetividade.

É igualmente importante que a posições e as opiniões dos plut, šut e durak não precisem de justificativa aos olhos do leitor. Como diz Bakhtin, já no folclore, essas três figuras tinham um status idêntico, e, a esse respeito, há muito ele utiliza a expressão glubiny doklassovogo fol'klora (as profundezas do folclore da sociedade primitiva sem classes) (Ibid., p. 194). E mesmo que na linha seguinte Bakhtin especifique que o problema da gênese dos personagens folclóricos correspondentes não o interessa, ao final do capítulo, ele insiste sobre a necessidade de estudar os papéis e as funções dos plut, šut e durak, assim como sua gênese. É necessário, diz, considerar a grande importância desses personagens na "consciência coletiva" dos diferentes povos e estudar seus traços particulares, assim como sua "cor local" nas diferentes "tradições".

Seguindo esse conselho de Bakhtin endereçado a futuros pesquisadores, vamos nos dedicar aos plut, šut e durak na "tradição" folclórica e cultural russa (mais precisamente, estudaremos os dados contidos nos dicionários de língua e dos provérbios russos de V.I. Dahl [1863-1866 e 1861-1862, respectivamente]) para buscar compreender em que medida a imagem "russa" dessas figuras pôde influenciar o próprio conteúdo do sexto capítulo das Formy vremeni $i$ xronotopa v romane.

Assinalemos, inicialmente, que a leitura atenta desse capítulo mostra que o "trio" plut/šut/durak divide-se várias vezes em "šut + durak", de um lado, e "plut", de outro. Essa tendência se manifesta não somente nos exemplos específicos da utilização das três noções correspondentes por Bakhtin, mas também nas explicações apresentadas por ele no início do capítulo: o plut, diz Bakhtin, mantém relações com a realidade, enquanto o šut e o durak estão distantes das coisas deste mundo (Ibid., p. 195). Essa mesma situação reconstrói-se, em parte, a partir do estudo dos fatos da língua e do folclore russos. Dediquemo-nos à análise das palavras russas correspondentes.

Antes de nos apoiarmos nos dados do russo moderno, vamos analisar seu estado mais antigo, cristalizado, em particular, no Dictionnaire raisonné de la langue russe de V.I. Dahl.

Com efeito, o plut, nesse dicionário, está "relacionado" ainda à realidade, às leis e às normas da vida social. É verdade que ele as infringe, mas a negação das normas e das regras socialmente estabelecidas não supõe a própria existência destas últimas, assim como sua compreensão pelo violador?

Dahl define o plut como "aquele que afana e logra, enganador astucioso e hábil, velhaco, malandro, pessoa desonesta, sobretudo nas pequenas coisas ${ }^{5}$. A última parte dessa definição mostra que o plut não pode, de maneira alguma, se igualar a um criminoso que amedronta as pessoas. Ao contrário, há até algo engraçado e divertido, e mesmo agradável nesse personagem, daí a frequência importante da utilização das formas diminutivas desse nome em russo (como plutiša, plutec [pequeno plut], etc.). Assim, um ditado russo diz: Ne dušoj xud, a prosto plut (ele não é mau, é apenas um plut) ${ }^{6}$. A etimologia popular une com frequência a palavra plut aos verbos russos que têm formas semelhantes bluždat', zabludit'sja (se desorientar, se perder, perder o rumo) $)^{7}$. O plut seria, portanto, aquele que se desorientou, que perdeu o

\footnotetext{
${ }^{4}$ A partir de agora, utilizaremos os lexemas russos transliterados, em vez das palavras em português correspondentes trapaceiro/vilão, bufão e bobo.

${ }^{5}$ V.I. Dahl, Tolkovyj slovar' živogo velikorusskogo jazyka [1863-1866], Gosudarstvennoe izdatel'stvo inostrannyx i nacional'nyx slovarej, Moscou, 1956, vol. I-IV; vol. III, p. 130.

${ }^{6}$ V.I. Dahl, Poslovicy russkogo naroda [1862], Xudožestvennaja literatura, Moscou 1989, vol. I-II; vol. I, p. 136. A esse respeito, lembremo-nos de um tipo particular de contos "novelísticos" (novellističeskie skazki) que V.Ja. Propp distingue: trata-se dos contos sobre os astuciosos ladrões (fripons) (lovkie vory) (V.Ja. Propp, Russkaja skazka, [anos de 1960], Moscou, 2000; p. 305-313). Os personagens principais desses contos, "com tudo o que eles fazem, satisfazem o sentido[...] de justiça, zombando dos fortes deste mundo e humilhando-os" (ibid., p. 307).

${ }^{7}$ Aliás, na língua russa do século XVII, o verbo plutat' tinha o sentido de "errar", "se enganar", assim como "roubar, ludibriar", conforme S.G. Barxudarov, F.P. Filin, D.N. Šmelev, G.A. Bogatova, et al., Slovar' russkogo jazyka XI - XVII vekov, Nauka, Moscou, 1975 - ..., vol. I - ...; vol. XV, p. 110-111. No Dictionnaire étymologique de la langue russe de M. Fasmer, indica-se que a palavra plut pode ser o resultado de uma contaminação de plutat' e plesti (confundir e tramar, respectivamente) (M. Fasmer [Vasmer], Ėtimologičeskij slovar' russkogo jazyka. Moscou, 1986-1987, vol. I-IV; vol. III, p. 288).
}

Organon, Porto Alegre, $\mathrm{n}^{\circ}$ 47, julho-dezembro, 2009, p.85 - 94 
rumo (na vida?). Como, em geral, a pessoa desorientada nem sempre é responsável por seus infortúnios, o plut se vê, de alguma maneira, senão perdoado, pelo menos implicitamente justificado pela sociedade: não seria culpa sua se ele se tornou um pequeno vigarista. Isso explica uma atitude indulgente dos indivíduos diante do plut, assim como, novamente, as indicações existentes sobre seus laços com a vida social (por exemplo em Dahl, conforme a expressão vplutovat'sja v obščestvo - "trapacear" na boa sociedade, isto é, "penetrar na boa sociedade enganando as pessoas"8).

Os personagens russos šut e durak parecem mais complexos. Além disso, eles estão realmente unidos um ao outro. Assim, o durak é definido por Dahl como uma pessoa estúpida, um teimoso, um insensato ${ }^{9}$. Essas características eram normalmente consideradas partes integrantes da pessoa em questão: era impossível se desvencilhar delas (conforme a estupidez orgânica dos bobos naturais). Por exemplo, isso é comprovado pelos provérbios russos p'janyj prospitsja, a durak nikogda (aquele que fica bêbado não ficará mais depois de ter dormido até não poder mais, mas o durak ficará assim para sempre ${ }^{10}$ ), duraka učit' - čto mertvogo lečit' (ensinar um durak é o mesmo que ressuscitar um morto ${ }^{11}$ ), duraka učit' rešetom vodu nosit (ensinar um durak é o mesmo que carregar água em uma peneira (Ibid), duraka učit' čto na vode pisat' (ensinar um durak é o mesmo que escrever na água (Ibid.), kogda solnce orla požret, kamen' na vode vsplyvet, svin'já na belku zalaet, togda durak poumneet (um durak apenas se tornará esclarecido quando o sol tiver comido uma águia, quando uma pedra tiver flutuado na água ou quando um porco tiver latido para um esquilo [isto é, nunca] (Ibid).).

Por outro lado, o durak, à época de Dahl (hoje esta parte da significação de tal palavra russa está esquecida ${ }^{12}$, ainda significava šut (bufão, truão, aquele que ganha a vida fazendo bobagens, comportando-se como um bufão ${ }^{13}$ ). Do mesmo modo, Dahl definia o šut como aquele que vive de brincadeiras, de piadas e tolices. O šut, escreve Dahl, finge ser bobo e mostra-se espirituoso ao carregar essa máscara ${ }^{14}$. Assim, o šut usa uma máscara de durak que o ajuda a ganhar a vida. O elo entre as noções durak, šut e glupost' (tolice, palermice, estupidez) se manifesta igualmente em algumas expressões fixas citadas por Dahl (como, por exemplo, glupaja šutka [brincadeira estúpida(Ibid., p. 650)], etc.), assim como no provérbio $i$ duraku ne vsjakaja šutka $k$ licu (mesmo um durak não pode fazer certas brincadeiras ( Ibid), etc.).

Bakhtin opunha as galhofas do šut (Baxtin, op. cit., p. 197) e a incompreensão ingênua do durak (Ibid., p. 198.) aos engodos e à hipocrisia da sociedade medieval com todas suas convenções, sendo o šut e o durak representados como reveladores da verdade, daquilo que é verdadeiro na vida. Ora, a imagem de šut na Rússia era outra.

Segundo Dahl, ao contrário, šut era aquele que dizia mentiras (mesmo que o fizesse para gracejar, e não pela mentira em si) para ganhar a vida ${ }^{15}$ (daí, por exemplo, a expressão vyšutit' sebe podačku [ganhar uma esmola bancando o bufão (Ibid.), assim como o ditado ne vyslužis', tak vyšutiš [o que tu não ganharás trabalhando, tu ganharás bancando o bufão $\left.{ }^{16}\right]$ ).

Isso explica as relações do šut com o mundo irreal e imaginário: em suas brincadeiras, não há e não pode haver verdade. Não deve ser um acaso que os provérbios russos oponham a verdade à brincadeira: pravda šutki ne ljubit (a verdade não gosta de brincadeiras), s pravdoj ne šuti (não se deve brincar com a verdade), s pravdoj šuti - čto s ognem (brincar com a verdade é como brincar com fogo ${ }^{17}$ ), $v$ šutkax pravdy ne byvaet, $v$ šutkax pravdy net (não existe verdade nas brincadeiras), šutu ne ver (não se pode

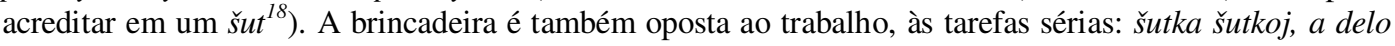
delom (brincadeira é uma coisa, o trabalho é outra), šutki v storonu, pogovorim del'no (brincadeiras à parte, falemos seriamente ( Ibid.)). Assim, o šut é considerado um mau amigo e, em geral, um companheiro infiel: šut $v$ družbe neveren (um šut não é um fiel amigo (Ibid.)), bojarin šutu rad, da s nim ne xodit $v$ rjad (mesmo que o boiardo esteja feliz com seu šut, este nunca será seu companheiro (Ibid., p. 335.)), etc.

\footnotetext{
${ }^{8}$ V.I. Dahl, Tolkovyj slovar' živogo velikorusskogo jazyka, op. cit., vol. III, p. 131.

${ }^{9}$ Ibid., vol. I, p. 501. Etimologicamente a palavra durak está relacionada à semântica do "impetuoso", conforme M. Fasmer, op. cit., vol. I, p. 555.

${ }^{10}$ V.I. Dahl, Tolkovyj slovar' živogo velikorusskogo jazyka, op. cit., vol. I, p. 501.

${ }^{11}$ V.I. Dahl, Poslovicy russkogo naroda, op. cit., vol. I, p. 383.

${ }^{12}$ Conforme S.I. Ožegov, Slovar' russkogo jazyka, 18 izdanie, Russkij jazyk, Moscou, 1987, p. 156-157.

13 V.I. Dahl, Tolkovyj slovar' živogo velikorusskogo jazyka, op. cit., vol. I, p. 501. Esse mesmo sentido é revelado em S.G. Barxudarov, F.P. Filin, D.N. Šmelev, G.A. Bogatova, et al., op. cit., vol. IV, p. 377. Aliás, se na origem de durak é encontrada a semântica do "impetuoso" (conforme nota 14), šut pode estar etimologicamente relacionado ao verbo que significa "descontrolarse", conforme M. Fasmer, op. cit., vol. IV, p. 491.

${ }^{14}$ V.I. Dahl, Tolkovyj slovar' zivogo velikorusskogo jazyka, op. cit., vol. IV, p. 649

${ }^{15}$ V.I. Dahl, Tolkovyj slovar' živogo velikorusskogo jazyka, op. cit., vol. IV, p.650.

${ }^{16}$ V.I. Dahl, Poslovicy russkogo naroda, op. cit., vol. II, p. 335.

${ }^{17}$ V.I. Dahl, Tolkovyj slovar' živogo velikorusskogo jazyka, op. cit., vol. IV, p.649.

${ }^{18}$ V.I. Dahl, Poslovicy russkogo naroda, op. cit., vol. II, p. 336. 
Todas essas conotações negativas do šut podem ser explicadas pelo fato de que ele era ligado ao mundo do além, ao diabo e aos espíritos malignos, hostis ao homem. São eles que brincam (̌̌utjat - se comportam como um šut) na maioria das vezes nos provérbios e nos ditados russos: čem čert ne šutit (o diabo brinca com tudo), s ostrogolovym (čertom) ne šutit: peretjanet (não se deve brincar com o diabo: ele sempre ganha), šutit' by čertu so svoim bratom (se ao menos o diabo brincasse só com seu irmão...), šutil by čert s lešim, vodjanoj s besom (se ao menos o diabo brincasse só com os demônios, e o espírito das águas, com os silvanos), lešij pošutit - domoj ne pustit, vodjanoj pošutit - utopit (brincando, o silvano não te deixará voltar para casa, e o espírito das águas te afogará (Ibid., p. 337)). Nos ditados russos, a palavra šut é muitas vezes utilizada como um eufemismo para diabo: šut ego beri (que o diabo [šut] o carregue), nu ego, $k$ šutu (que ele vá para o diabo [em direção ao šut] ${ }^{19}$ ), etc. Em Dahl, encontra-se também a expressão $v$ ètot lês xodi, tam šutit (não se deve entrar nesta floresta onde se brinca ["se" age como $\check{s} u t]^{20}$ ). Igualmente, o motivo da remissão do mal a outro mundo, freqüente nos textos das palavras mágicas russas $^{21}$, repete-se também nos provérbios sobre as brincadeiras, por exemplo: pivô pivom, delo delom, a šutka podi $v$ čužuju derevnju (uma cerveja é uma cerveja, um negócio é um negócio, e tu, brincadeira, vá para fora daqui ${ }^{22}$ ). Por isso, brincar remete ainda frequentemente a "perturbar", no sentido de "desviar", "desconcertar": šutki šutit - ljud'mi mutit' (brincar com as pessoas é igual a confundi-las (Ibid.)), xorošo pušutil, narod pomutil (ele brincou muito, perturbou todos ${ }^{23}$ ). Em geral, šutka v dobro ne vvedet (brincadeiras não levam ao bem ${ }^{24}$ ).

Era uma das razões das perseguições constantes dos skomoroxi-šuty (histriões - bufões - triões) pela Igreja na Rússia. Os skomoroxi eram atores itinerantes que, em geral, compunham eles próprios canções satíricas e burlescas para cantar. Skomorošestvo; a bufonaria surgiu na Rússia em torno do século XI, se desenvolveu durante quatro séculos e perdurou até o século XVIII: em 1648 e 1657, o Estado russo, sob a influência da Igreja Ortodoxa, estabeleceu os éditos que interditavam a bufonaria ${ }^{25}$.

O motivo da brincadeira era muitas vezes ligado àquele da morte na Rússia: šutnik pokojnik: pošutil da pomer (o morto brinca: ele brincou e morreu ${ }^{26}$ ). Os exemplos dos laços semânticos do riso com a morte são muito frequentes no folclore russo. Já a etimologia popular unia essas duas palavras russas, devido à semelhança impressionante entre suas formas: smex (o riso) e smert' (a morte). Ora, a noção do riso era igualmente ligada ao durak: duraku vse smex na ume. Duraku vse smešo (o durak só pensa em rir). O durak ri por qualquer coisa (iz duraka i plač smexom pret, mesmo chorando ele ri; ele ri mesmo quando chora. (ibid., vol. I, p. 386)), etc.

Entretanto, à diferença do šut que fingia ser durak (conforme bobo artificial) e que era ligado, no folclore, ao diabo e ao mundo do além, o verdadeiro durak (bobo natural) despertava antes a piedade da parte do povo e era considerado uma pessoa amada por Deus: umnyj sam po sebe, a duraku bog na pomoč (o sábio ajuda a si mesmo, mas o durak é amado por Deus), na duraka u boga milosti mnogo. Durakbožij čelovek (o bom Deus é muito gentil com o durak. O durak é amado por Deus), mnogo uma mnogo grexa, a na durake nečego vzjat' (muito espirituoso, muitos pecados, mas o durak não é responsável por nada), popa da duraka - v perednij ugol sažajut (os melhores lugares são para o padre e para o durak ( Ibid., p. 385)). Nos contos populares russos, também é precisamente o durak que vence, que se casa com uma bela princesa e que se torna rei, enquanto seus irmãos sábios fracassam ${ }^{27}$.

Eis, então, o que o estudo do "trio" russo plut, šut e durak mostra:

\footnotetext{
${ }^{19}$ V.I. Dahl, Tolkovyj slovar' živogo velikorusskogo jazyka, op. cit., vol. IV, p.650.Também é o lobo que brinca muitas vezes nos ditados e provérbios russos: ora, na "tradição" folclórica russa, a palavra volk (lobo) era também um eufemismo para "diabo" (conforme A.V. Gura, Simvolika životnyx v slavajanskoj tradicii, Indrik, Moscou, 1997, p. 128 e demais).

${ }^{20}$ V.I. Dahl, Tolkovyj slovar' živogo velikorusskogo jazyka, op. cit., vol. IV, p.649. Se brinca é aqui uma construção impessoal em que se remete ao 'diabo': 'o diabo brinca'.

${ }^{21}$ Conforme E. Velmezova, "Semantika prostranstva lečebnogo zagovora: k tipologii formul otsylki bolezni (na primere vostočnoslavjanskix, češskix i francuzskix tekstov)", in Vestnik MGU, serija 9, Filologija, 1999, no 4, p. 50-60.

${ }^{22}$ V.I. Dahl, Poslovicy russkogo naroda, op. cit., vol. II, p. 336.

${ }^{23}$ V.I. Dahl, Tolkovyj slovar' żivogo velikorusskogo jazyka , op. cit., vol. IV, p.649.

${ }^{24}$ V.I. Dahl, Poslovicy russkogo naroda, op. cit., vol. II, p. 336. V. Ja. Propp distingue os contos sobre os bufões malvados como um tipo particular de contos "novelísticos" (V. Ja. Propp, Russkaja skazka, op. cit., p. 330). Com suas brincadeiras cruéis, os bufões podiam provocar a morte, assim como vários males (ibid., pp. 330-333). Segundo a classificação de diversos tipos de riso em Propp (conforme V. Ja. Propp, Problemy komizma i smexa. Ritual'nyj smex v fol'klore [fim dos anos de 1960], Labirint, Moscou, 1999), o próprio riso dos bufões é cruel e cínico (ibid., pp. 158-161). Não tendo nada em comum com um riso bondoso e alegre, ele é muitas vezes fonte de sofrimentos (ibid., p. 160).

${ }^{25}$ Conforme A.A. Belkin, Russkie skomoroxi, Moscou, 1975 e R.A. Šames « Sobiratel'nyj obraz skomoroxa i russkaja literatura", in Hermeneutics in Russia, 1998, issue 3, vol. 2 (www.tversu.ru/Science/Hermeneutucs/1998 -3/1998-3-04.pdf).

${ }^{26}$ V.I. Dahl, Poslovicy russkogo naroda, op. cit., vol. II, p. 335.

${ }^{27}$ Conforme, em particular, E.M. Meletinskij, Geroj volšebnoj skazki, Akademija issledovanij kul'tury, Moscou, 2005 e V.Ja. Propp, Russkaja skazka, op. cit., p. 210. Essa tendência é típica, sobretudo para os contos mágicos (segundo V.Ja. Propp, Russkaja skazka, op. cit., pp. 212-256), diferentemente dos outros tipos de contos onde o durak não somente ganha (ibid,, pp. 296, 323-324), mas às vezes perde (ibid., p. 324); também, de acordo com o artigo de L. Rubini Messerli presente nesta coletânea.

Organon, Porto Alegre, $n^{\circ} 47$, julho-dezembro, 2009, p.85 - 94
} 
1) Todos esses personagens são ligados, de uma maneira ou de outra, à vida social. Esse elo está mais manifesto no caso do plut (o que Bakhtin, aliás, havia também destacado). Entretanto, enquanto bobos artificiais, šut e durak tampouco são completamente estranhos à dimensão social da vida, mesmo que eles estejam ao mesmo tempo relacionados ao mundo do além;

2) Nos níveis etimológico e semântico, esses três personagens estão ligados um ao outro, o que os fatos da história da língua russa revelam - mesmo que, nessa circunstância, os laços sejam mais evidentes entre šut e durak;

3) No que tange aos personagens $\check{s} u t$ e durak, Bakhtin praticamente não estabelece diferenças entre os dois. Entretanto, ao contrário do šut russo que finge ser durak para ganhar a vida e que representa o lado sombrio e infernal do além-mundo, o verdadeiro durak (um bobo natural) está ligado ao lado divino e positivo desse mundo imaginário.

Uma análise mais detalhada do papel desses personagens na cultura russa (inicialmente, na literatura e no folclore) deverá permitir estudos futuros a respeito de seus papéis de maneira mais aprofundada.

\section{Bibliografia}

BARXUDAROV, S.G; FILIN, F.P.; ŠMELEV, D.N.; BOGATOVA, G.A. et al. Slovar' russkogo jazyka XI - XVII vekov. Moscou, Ed. Nauka, 1975, vol. I-XV.

BAXTIN, M.M. Formy vremeni i xronotopa v romane. Očerki pó istoričeskoj poètike (1937-1938). In: Baxtin, M.M. Literaturnokritičeskie stat'i. Moscou, Xudožestvennaja literature, 1986, p. 121-290.

BELKIN, A.A. Russkie skomoroxi. Moscou, Ed. Nauka, 1975.

BODUÈN DE KURTENÈ, I.A. Jazykoznanie, ili lingvistika, XIX veka (1901). In: Boduèn de Kurtenè, I.A. Izbrannye trudy. Moscou, Ed. Izdatel'stvo Akademii nauk, 1963, vol. I-II.

DAHL, V.I. Poslovicy russkogo naroda (1862). Moscou, Xudožestvennaja literatura, 1989, vol. I-II.

DAHL, V.I. Tolkovyj slovar' živogo velikorusskogo jazyka (1863-1866). Gosudarstvennoe izdatel'stvo inostrannyx i nacional'nyx slovarej, Moscou, 1956, vol. I-IV.

FASMER [Vasmer], M. Ėtimologičeskij slovar' russkogo jazyka. Moscou, Ed. Progress, 1986-1987, vol. I-IV.

GURA, A.V. Simvolika životnyx v slavajanskoj tradicii. Moscou, Ed. Indrik, 1997.

MARR, N.Ja. Jazykovaja politika jafetičeskoj teorii i udmurtksij jazyk. (k udmurtskoj èkspedicii Naučnoissledovatel'skogo instituta narodov Sovetskogo Vostokaj) (1931). In: Marr, N.Ja. Izbrannye raboty. 1933-1937, vol. I-V, Izdatel'stvo gosudarstvennoj akademii istorii material'noj kul'tury (vol. I)Gosudarstvennoe social'no-èkonomičeskoe izdatel'stvo (vol. II-V), Moscou -Leningrad, vol. V, p. 467533.

MELETINSKIJ, E.M. Geroj volšebnoj skazki. Moscou, Ed. Akademija issledovanij kul'tury, 2005.

OŽEGOV, S.I. Slovar' russkogo jazyka, 18 izdanie. Moscou, Russkij jazyk, 1987.

PROPP, V.Ja. Problemy komizma i smexa. Ritual'nyj smex v fol'klore. Moscou, Ed. Labirint, 1999.

PROPP, V.Ja. Russkaja skazka. Moscou, Ed. Labirint, 2000.

ŠAMES, R.A. Sobiratel'nyj obraz skomoroxa i russkaja literature. In: Hermeneutics in Russia, 1998, issue 3, vol. 2 (www.tversu.ru/Science/Hermeneutucs/1998 -3/1998-3-04.pdf).

ŠCERBA, L.V. Sur la notion de mélange des langues. Jafetičeskij sbornik, 1925, vol. IV, p. 1-19.

SCHUCHARDT-BREVIER, H. Ein Vademekum der allgemeinen Sprachwissenschaft/als Festgabe zum $8^{o}$. Geburtstag des Meisters zusammengestellt und eingeleitet von Leo Spitzer, Verlag Max Niemeyer, Halle (Saale), 1922, p. 128-141.

VELMEZOVA, E. Mikhail Bakhtin, o mecânico e as fronteiras. In: Zandwais, A. ( org.), Ensaios: Mikhail Bakhtin. Contribuições para a Filosofia da Linguagem e Estudos Discursivos. Porto Alegre, Ed. Sagra Luzzatto, 2005, p. 73-82. Traduzido por Ana Zandwais

. Mixail Baxtin, Nikolaj Marr i paradigma 'celostnoj nauki'. In: LÄHTEENMÄKI et alli. ( orgs.), Proceedings of the XII International Bakhtin Conference. Juväskylä, Finland, 18-22 july 2005, Finland, Department of Languages, University of Juväskylä, , 2006, p. 62-77.

Semantika prostranstva lečebnogo zagovora: k tipologii formul otsylki bolezni (na primere vostočnoslavjanskix, češskix i francuzskix tekstov). Vestnik $M G U$, serija 9, Filologija, 1999, no 4, p. 5060.

VESELOVSKIJ, A.N. Tri glavy iz istoričeskoj poètiki (1899). In: Veselovskij, A.N. Istoričeskaja poètika. Moscou, Èditorial URSS, 2004, p. 200-380. 
Traduzido por Janaína Pinto Soares sob a coordenação da Profa. Dra. Patrícia Reuillard (Depto. de Línguas Modernas - UFRGS) 